\title{
Experimental examination of the melt embayment method for determining magma decompression \\ rate
}

\author{
R. DEGRAFFENRIED ${ }^{1, *}$, N. CLUZEL ${ }^{2}$, T. SHEA ${ }^{1}$, J. \\ HAMMER $^{1}$
}

${ }^{1}$ University of Hawaii at Manoa, Honolulu, HI 96822, USA

(*correspondence: rdegraff@hawaii.edu)

${ }^{2}$ Laboratoire Magmas et Volcans, Université Clermont, Auvergne, France

The rate at which magma decompresses in transit to the Earth's surface has a first-order control on eruption style as it dictates the time available for dissolved volatile elements (e.g., $\mathrm{H}_{2} \mathrm{O}, \mathrm{CO}_{2}$ ) to exsolve to a separate phase. Though decompression rate is difficult to determine, one promising technique exploits volatile concentration gradients in melt embayments as an output constraint for diffusion models. The procedure is to find the best-fitting diffusion profile for a given measured concentration gradient, assuming parameters for the conditions of ascent. This calculates the time needed to produce the measured gradient. Although this technique is gaining acceptance, few confirmations exist to quantify the conditions (e.g., decompression rate, geometry) under which this technique can reproduce the decompression rate that created the measured gradients. The error introduced to calculated timescales by model simplifications has recently been explored numerically, but experiments are needed to determine whether nature behaves as the models expect.

We conducted high pressure-temperature decompression experiments with variable decompression rates to test whether a) diffusion modeling yields comparable $\mathrm{dP} / \mathrm{dt}$ and b) the technique is applicable to a broad range of $\mathrm{dP} / \mathrm{dt}$. The experiments used both powdered and obsidan core starting material of the Güney Daği rhyolite, Turkey (76.5 wt. \% $\mathrm{SiO}_{2}$ [1]). Artificial embayments were examined using single-bore alumina tubing, which eliminates geometry variation between experiments as a variable. Embayment diameters, as dictated by the alumina tubes, are $500 \mu \mathrm{m}$ and $300 \mu \mathrm{m}$, permitting us to evaluate the effect of scaling on modeling results. Experiments were hydrated at $200 \mathrm{MPa}$ and $800^{\circ} \mathrm{C}$ for 5 days to ensure full saturation of the obsidian core, then decompressed at variable rates $(0.01-1 \mathrm{MPa} / \mathrm{s})$ to $50 \mathrm{MPa}$ and rapidly quenched. Raman mapping of experiments will provide an output constraint for 2D and 1D diffusion models, and the modeled timescale will be compared to the known imposed decompression timescale.

[1] Mourtada-Bonnefoi and Laporte (2002) J. Geophyis. ResSol. Ea. 107. 